\title{
Computer-aided three-dimensional assessment of periodontal healing distal to the mandibular second molar after coronectomy of the mandibular third molar: a prospective study
}

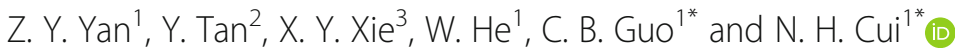

\begin{abstract}
Background: The periodontal healing distal to the mandibular second molar (M2M) after coronectomy of the M3M has shown controversial results. We aimed to combine a digital method with cone-beam computed tomography $(\mathrm{CBCT})$ and estimate periodontal healing of M2M after M3M coronectomy. An accurate and stable indicator in three dimensions was also explored tentatively.

Methods: Patients with a M3M in contact with the inferior alveolar canal were included. CBCT was applied immediately after coronectomy (baseline) and 6-months later. Data were investigated with digital software for registration. Previously reported and coronectomy-related factors were included for univariate and multivariate analyses.
\end{abstract}

Results: A total of 181 patients (213 M3Ms) completed 6-month follow-up. Significant reduction in the distal intrabony defect (DBD) depth of the M2M was shown $(1.28 \pm 1.24 \mathrm{~mm}, P<0.001)$. DBD depth of the M2M at baseline was the most influential factor $(r=0.59)$, followed by preoperative M3M condition, age, rotation and migration of the root complex. Remaining enamel $(\mathrm{OR}=6.93)$ and small retromolar space $(0.67)$ contributed to re-contact of the root complex and M2M. Bone volume regenerated in the distal $2 \mathrm{~mm}$ was associated significantly with DBD-depth reduction $(r=0.74, P<0.001)$.

Conclusions: Bone volume regenerated in the distal $2 \mathrm{~mm}$ of the M2M denoted stability of distal periodontal healing of the M2M. DBD depth at baseline was the most influential factor for healing of a DBD of the M2M after M3M coronectomy. The remaining enamel and a small retromolar space could contribute to re-contact of the root complex and the M2M.

Trial registration: China Clinical Trial Center, ChiCTR1800014862. Registered 10 February 2018,

(Continued on next page)

\footnotetext{
* Correspondence: chuanbinguo@pkuss.bjmu.edu.cn; drcuinianhui@163.com 1 Department of Oral and Maxillofacial Surgery, Peking University School and Hospital of Stomatology, 22 South Street Zhong Guan Cun, Haidian District, Beijing 100081, China

Full list of author information is available at the end of the article
}

(c) The Author(s). 2020 Open Access This article is licensed under a Creative Commons Attribution 4.0 International License, which permits use, sharing, adaptation, distribution and reproduction in any medium or format, as long as you give appropriate credit to the original author(s) and the source, provide a link to the Creative Commons licence, and indicate if changes were made. The images or other third party material in this article are included in the article's Creative Commons licence, unless indicated otherwise in a credit line to the material. If material is not included in the article's Creative Commons licence and your intended use is not permitted by statutory regulation or exceeds the permitted use, you will need to obtain permission directly from the copyright holder. To view a copy of this licence, visit http://creativecommons.org/licenses/by/4.0/. The Creative Commons Public Domain Dedication waiver (http://creativecommons.org/publicdomain/zero/1.0/) applies to the data made available in this article, unless otherwise stated in a credit line to the data. 
(Continued from previous page)

Keywords: Coronectomy, Computer-aided 3D assessment, Distal intra-bony defect, Periodontal healing, Re-contact, volume of bone regenerated

\section{Background}

"Coronectomy" is an alternative to total extraction of the mandibular third molar (M3M) to protect the inferior alveolar nerve (IAN) [1, 2]. Coronectomy is applied mainly to a deeply impacted M3M vulnerable to a distal intra-bony defect (DBD) of the mandibular second molar (M2M) after M3M surgery [3]. Just as in total extraction, the prognosis of a DBD continues to challenge clinicians [4]. Most studies have claimed that a DBD of the M2M remains unchanged or improves [5-7] but several other studies have suggested that this condition worsens after M3M surgery [8]. The reason for this difference could be because of an unsatisfactory design of the clinical study $[9,10]$ and/or limitations in periodontal-probing factors (pocket depth and attachment loss).

Most studies on M2M conditions after M3M surgery have focused only on the indicators of periodontal probing $[11,12]$. In fact, the accuracy of subjective recording would be affected by unsatisfactory vision in the posterior oral cavity and variable location of the gingival margin [13-15]. Conversely, indicators of periodontal probing cannot eliminate interference due to repair of the long-junctional epithelium, which is characterized as repair or very limited regeneration [16].

Compared with indicators of periodontal probing, bone levels on radiography seem more stable. Faria used the cementoenamel junction (CEJ) as a reference to assess the DBD of the M2M on digital periapical radiographs, and obtained a relatively stable result [10]. However, due to the overlap of two-dimensional (2D) imaging, changes in bone height on the buccal and lingual sides could not be measured separately [17]. In addition, changes in bone height could barely reflect the possibility of further bone resorption. An accurate and predictable indicator in three dimensions is needed.

Recently, a combination of 3D cone-beam computed tomography $(\mathrm{CBCT})$ data and digital software has enabled the reconstruction and registration of digital models of tooth or bone. This approach has provided excellent reproducibility and accuracy for comparative analyses [18, 19]. Guidance of implant surgery [20] and navigation of oral and maxillofacial surgery [21] can employ this new method.

We used a digital method to evaluate the DBD prognosis of the M2M after M3M coronectomy. Previously reported factors and coronectomy-related factors were included. In addition, an accurate and stable indicator in three dimensions was explored tentatively.

\section{Methods}

This was a single-arm and single-blinded study. It is also part of an ongoing study on the long-term changes in the M3M after coronectomy [2]. Ethical approval of the study protocol was granted by the Biomedical Ethics Committee of Peking University Hospital of Stomatology (PKUSSIRB-201736080) in Beijing, China. This study was conducted in accordance with the Helsinki Declaration of 1975, as revised in 2013 and registered in the China Clinical Trial Center (ChiCTR1800014862). All patients provided written informed consent to participate in this study.

\section{Eligibility}

From 2018 to 2019, patients who accepted coronectomy of an impacted M3M were recruited from the Department of Oral \& Maxillofacial Surgery of Peking University School and Hospital of Stomatology.

Inclusion criteria were: (i) healthy males and females aged 18-40 years; (ii) a M3M impacting the inferior alveolar canal, as shown by preoperative CBCT; (iii) the patient could tolerate surgery.

Exclusion criteria were: (i) local susceptible factors such as caries, cystic/neoplastic conditions around the M3M; (ii) periodontal condition of the M2M: mesial alveolar bone resorption $>1 / 3$ of root length, loose tooth, or smoking > 10 cigarettes per day [22]; (iii) general systemic disease contributing to infection (e.g., diabetes mellitus, immunodeficiency); (iv) history of radiotherapy or chemotherapy; (v) pregnancy.

The sample size for this study was calculated using SAS v8.3 (SAS Institute, Cary, NC, USA). The DBD depth of M2M before M3M coronectomy has been reported as $6.1 \pm 2.8 \mathrm{~mm}$ [14]. To observe a difference of $0.5 \mathrm{~mm}$ in postoperative radiographs with a power of $90 \%$ at the $5 \%$ significance level, the sample size should be $\geq 137$ subjects. Considering an anticipated dropout rate of $20 \%$, a sample size of 172 subjects was necessary.

\section{Surgical procedure and imaging}

During coronectomy, we applied a crown section 1-2 $\mathrm{mm}$ below the CEJ. The root surface was trimmed to $\geq 3$ $\mathrm{mm}$ below the alveolar crest $[1,23]$. After routine root planing of the $\mathrm{M} 2 \mathrm{M}$, debridement and irrigation, the wound was sutured. All surgical procedures were undertaken by the same senior surgeon. Neither antibiotics nor analgesic were administered. 
CBCT was done twice: the day after surgery (baseline) and 6 months postoperatively (Po.6 m). A NewTom ${ }^{\text {Tx }}$ CBCT system (Quantitative Radiology, Verona, Italy) was applied to scan the region of interest. The imaging parameters were $110 \mathrm{kVp}$ with a voxel size of $0.2 \mathrm{~mm}$ and field of view of $8 \mathrm{~cm} \times 12 \mathrm{~cm}$. The $\mathrm{mA}$ value was regulated automatically according to head size of each patient. The exposure time was 18-s each.

CBCT examination was carried out mainly to followup the condition of the M3M root complex after coronectomy $[15,23,24]$. Those data and analyses will be summarized in another report.

\section{Construction and measurement using the digital model Registration and deviation}

CBCT data in Digital Imaging and Communications in Medicine format at baseline and Po.6 m were imported into Mimics ${ }^{\mathrm{Th}} 19.0$ (Materialise Dental, Leuven, Belgium). Digital models of mandibular bone, extraction socket (a digital model of hard tissue containing the entire extraction socket), the M2M, and root complex of the M3M after coronectomy were segmented and saved in stereolithography file format for further analyses in GeoMagic ${ }^{\mathrm{Tm}}$ Studio 12 (3D Systems, Rock Hill, SC, USA) [19]. Models of mandible bone with clear anatomic markers were applied for registration according to the "Best-Fit Alignment" algorithm $[25,26]$. Hence, the relative migration and variation at two times (baseline and Po.6 $\mathrm{m})$ could be visualized directly. The geometric deviation of the M2M at different times was calculated according to the "Deviation" algorithm. Mean \pm SD values were recorded and the distribution of distance shown on a graphical color map [19] (Fig. 1a-c).

\section{Bone regeneration}

The volume of bone regeneration and variation in the DBD depth (distance from the CEJ to the bottom of the osseous defect) were measured respectively.

Total volume of bone regenerated in the tooth socket A new digital model was calculated using the "Boolean" algorithm to subtract the extraction-socket model at different times. It was assumed that there was no change in hard tissue surrounding the tooth socket in the 6 months after surgery, except for bone regeneration in the tooth socket. Hence, the difference between two models for the extraction socket could be regarded as the total volume of bone regenerated in the tooth socket (Fig. 1d).

Volume of bone regenerated in the distal $2 \mathrm{~mm}$ of the M2M The digital model of the M2M was imported into 3-matic Medical 11.0 (Materialise Dental) and its border was expanded by $2 \mathrm{~mm}$ in three dimensions according to the "Wrap" algorithm. The interaction part of

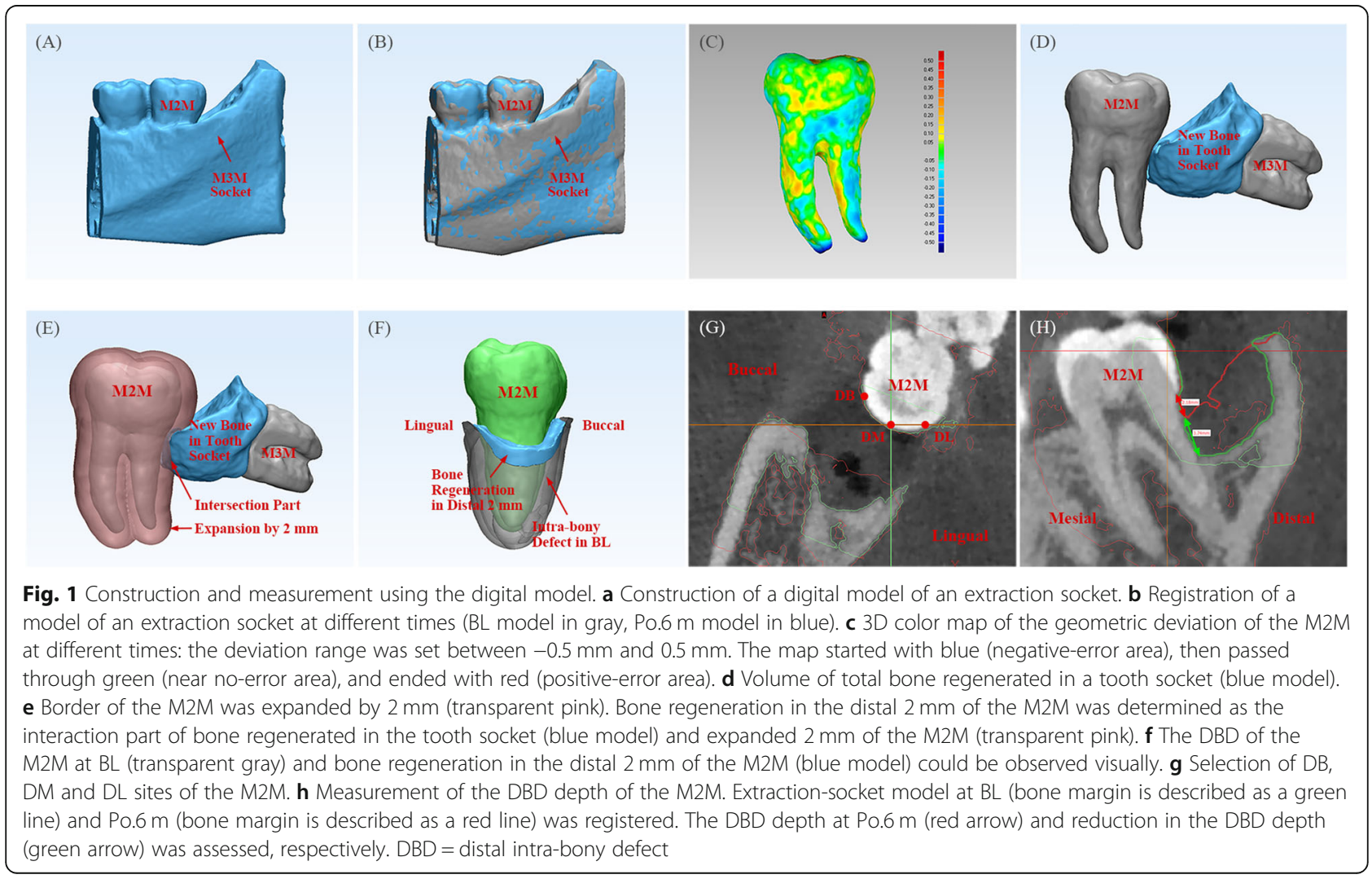


this new model and the model calculated above (total volume of bone regenerated in the tooth socket) was regarded as new bone regenerated in the distal $2 \mathrm{~mm}$ of the M2M (Fig. 1e, f). The reason why " $2 \mathrm{~mm}$ " was chosen is explained in the Discussion section.

Variation in DBD depth of the M2M Digital models of the extraction socket at different times, which had already been registered in GeoMagic, were imported into ProPlan $^{\text {Tw }}$ CMF (Materialize). The change in DBD depth was measured visually at the site of the disto-buccal (DB) axial angle and disto-lingual (DL) axial angle of the M2M. The disto-middle (DM) depth was measured pass the midpoint of the distal marginal ridge (DMR) of the M2M (Fig. 1g, h).

\section{Preoperative and postoperative variables}

All involved variables were measured and recorded by the same resident surgeon. To improve the accuracy of statistical analyses, the data were then transferred to other co-authors blinded to the study protocol for further analyses independently.

\section{Demographic characteristics}

The demographic characteristics were age and sex.

\section{M3M-related factors}

The M3M-related factors were: (i) Pell \& Gregory's depth of impaction; (ii) angulation of the M3M (the intersection angle of the M2M and M3M in the longitudinal axis was measured); (iii) retromolar space (RMS; calculated from the most distal point of the M2M to the anterior border of the ramus) [27].

\section{M2M-related factors}

There were four M2M-related factors. The first was DBD depth (baseline and Po. $6 \mathrm{~m}$ ). The second was the number of sites with DBD depth $\geq 4 \mathrm{~mm}$. The third factor was the probing depth (PD). This was measured with a periodontal probe (Hu-Friedy, Chicago, IL, USA) at DL, DM and DB sites. The DMR of the M2M was used as a stable reference instead of variable free gingival margins. Postoperatively, the PD was measured before wound suture and recorded as distance from the DMR to the bottom of the DBD. At Po.6 m, the PD was measured at a manual pressure of approximately $20-30 \mathrm{~g}$ and recorded as the distance from the DMR to the bottom of the gingival sulcus or pocket. The fourth factor was external root resorption.

\section{Coronectomy-related factors}

The coronectomy-related factors were: (i) distance of root migration; (ii) angle of root rotation; (iii) remaining enamel of the root complex; (iv) thickness of the calcification bridge (radioresistant bone-like structure above the root section): it was measured at the center of the root fragment; (v) eruption status of the root complex: soft-tissue coverage (root section was completely covered with soft tissue or partially by bone) and bony impaction (root section was completely covered with bone). (vi) total volume of bone regeneration in the tooth socket.

\section{Outcome parameters}

The outcome parameters were: (i) changes in the DBD depth; (ii) changes in the PD; (iii) volume of bone regenerated in the distal $2 \mathrm{~mm}$ of the M2M; (iv) whether the root complex re-contacted the distal surface of the M2M.

\section{Statistical analyses}

Statistical analyses were carried out using SPSS v21.0 (IBM, Armonk, NY, USA). Changes in the DBD depth and PD were analyzed using the paired $t$-test. Changes at sites with DBD depth $\geq 4 \mathrm{~mm}$ were analyzed using the chi-square test.

Outcome parameters were classified as continuous variables (changes in the $\mathrm{DBD}$ depth and $\mathrm{PD}$, volume of bone regenerated in the distal $2 \mathrm{~mm}$ of the M2M) and binary variables (root complex re-contacted at the distal surface of the M2M). For continuous variables, Kendall's tau-b correlation coefficient was applied as univariate analysis, followed by multiple linear regression as multivariate analysis. Chi-square tests, Mann-Whitney $U$ tests and binary logistic regression analysis were applied to binary variables. $P<0.05$ was considered significant.

\section{Results}

A total of 220 patients (coronectomies of 259 impacted M3Ms) were evaluated. However, 213 M3Ms of 181 patients (72 males and 109 females) completed follow-up at Po. $6 \mathrm{~m}$. The age (mean $\pm \mathrm{SD}$ ) of the study cohort was $27.03 \pm 4.84$ years.

The mean change in the DBD depth of the M2M (mean of DB, DM, DL sites) and volume of bone regenerated in the distal $2 \mathrm{~mm}$ of the M2M was $1.28 \pm 1.24$ $\mathrm{mm}$ and $39.75 \pm 26.03 \mathrm{~mm}^{3}$, respectively. The deviation of the digital registration was $0.01 \pm 0.25 \mathrm{~mm}$. Besides postoperative pain for a few days, all participants were asymptomatic at Po.6 m.

Although, no significant difference was found at baseline $(4.08 \pm 1.77$ vs. $4.45 \pm 1.56 \mathrm{~mm})(P=0.105)$, the reduction in the DBD depth in patients younger than 25 years was significantly larger than that in their older counterparts at Po. $6 \mathrm{~m}(1.55 \pm 1.35$ vs. $1.07 \pm 1.10 \mathrm{~mm})$ $(P=0.004)$. A significant decrease in the PD, DBD depth, and number of sites with DBD depth $\geq 4 \mathrm{~mm}$ was found at the distal sites $(\mathrm{DB}, \mathrm{DM}, \mathrm{DL})$ of the M2M $(P \leq 0.001)$ 
(Table 1). The correlation among periodontal variations at DB, DM and DL sites is shown in Fig. 2. The mean \pm $\mathrm{SD}$ of reduction in the PD and DBD depth, which was related significantly to variations at all distal sites (DB, DM, DL) of the M2M $(P \leq 0.001)$, was applied in further statistical analyses.

Kendall's tau-b correlation coefficient was applied to evaluate influential factors (Table 2). The DBD depth of the M2M at baseline was the factor (correlation coefficient $(r)=0.59)$ that was most influential to a reduction in the DBD depth at Po. $6 \mathrm{~m}$, followed by the preoperative M3M condition $(\geq 0.20)$, age $(-0.23)$ as well as the rotation status $(0.19)$ and eruption status $(0.27)$ of the root complex $(P \leq 0.003)$. Besides, the DBD depth of the M2M at baseline was associated significantly with the preoperative depth of M3M impaction $(r=0.15)$, angulation of the M3M (0.40) and DBD depth of the M2M at Po.6 m $(0.67)(P \leq 0.031)$. The RMS was related negatively with the preoperative depth of M3M impaction $(r=-0.28) \quad(P \leq 0.001)$. Similar influences were found for PD reduction and the volume of bone regenerated in the distal $2 \mathrm{~mm}$ of the M2M. Also, a level of correlation was shown between reduction in the DBD depth and the volume of bone regenerated in the distal $2 \mathrm{~mm}$ of the M2M $(r=0.74, P \leq 0.001)$ (Fig. 2).

Multiple linear regression models were established for factors influencing reduction in the DBD depth (adjusted $\left.R^{2}=0.592\right)$ and volume of bone regenerated in the distal $2 \mathrm{~mm}$ of the M2M (adjusted $\mathrm{R}^{2}=0.417$ ) (Table 3). Both factors were associated significantly with age, the RMS, the DBD depth at baseline, as well as the rotation and eruption status of the root complex at Po.6 m ( $P \leq$ 0.020 ). The total volume of bone regenerated in the tooth socket also influenced the volume of bone regenerated in the distal $2 \mathrm{~mm}$ of the M2M (coefficient: 0.14, $P=0.014$ ). Furthermore, the RMS (odds ratio $(\mathrm{OR})=$ $0.67)$ and remaining enamel of the $\mathrm{M} 3 \mathrm{M}(\mathrm{OR}=6.93)$ were significant factors influencing re-contact of the root complex with the M2M (19 in $213 \mathrm{M} 3 \mathrm{Ms})(P \leq 0.037)$.

PD measurement was not the distance from free gingival reduction to the bottom of the gingival sulcus or pocket. The difference between PD reduction and reduction in the DBD depth could represent the thickness of soft tissue above the bone defect. The regression model could better interpret PD reduction when soft-tissue variation was included (adjusted $R^{2}=0.798$ ) than when hard-tissue variation was included (0.618) (Table 4).

\section{Discussion}

The prognosis of a DBD of the M2M after M3M coronectomy has not been studied systematically and accurately previously. Only the effect of root migration and short-term complications of DBD variations have been analyzed with overlapped 2D radiography [14]. The influences of rotation, eruption status, and re-contact with adjacent teeth of the M3M root complex have been ignored, which are important and common coronectomyrelated cofactors [28]. In addition, Vignudelli observed $4 \pm 4 \mathrm{~mm}$ of bone regeneration 9 months after coronectomy, and claimed it was comparable with guided tissue regeneration after M3M extraction. They used a value of $3.59 \pm 1.14 \mathrm{~mm}$ reported by Hassan [13] as a comparison. A new study with three-dimensional (3D) measurements should be applied to validate these results.

We combined digital technology and CBCT (which overcame the limitation of periodontal probing and $2 \mathrm{D}$ radiography) to measure bone-level changes in three dimensions accurately. Our main finding was that periodontal healing of the M2M after M3M coronectomy would not be disturbed by the remaining root complex. The volume of bone regenerated in the distal $2 \mathrm{~mm}$ of the M2M was an effective indicator in three dimensions.

After registration of CBCT at baseline and Po.6 m, digital technology showed a significantly lower deviation $(0.01 \pm 0.25 \mathrm{~mm})$ than that using $2 \mathrm{D}$ radiography $( \pm 0.5$

Table 1 Variation in the PD and DBD depth between BL and Po. $6 \mathrm{~m}$ and difference between them

\begin{tabular}{|c|c|c|c|c|c|c|c|c|c|c|c|c|c|}
\hline & \multicolumn{3}{|c|}{ DBD depth $\geq 4 \mathrm{~mm}$} & \multicolumn{3}{|c|}{ DBD depth $(\mathrm{mm})$} & \multicolumn{3}{|l|}{ PD (mm) } & \multicolumn{4}{|c|}{ PD reduction vs DBD depth reduction $(\mathrm{mm})$} \\
\hline & $\overline{B L}$ & $\begin{array}{l}\text { Po.6 } \\
\mathrm{m}\end{array}$ & $\overline{P \text {-value }}$ & $\mathrm{BL}$ & Po.6 m & $P$-value & $\mathrm{BL}$ & Po.6 m & $P$-value & $\begin{array}{l}\mathrm{PD} \\
\text { reduction }\end{array}$ & $\begin{array}{l}\text { DBD depth } \\
\text { reduction }\end{array}$ & Difference & $P$-value \\
\hline & $\%$ & $\%$ & & $\begin{array}{l}\text { Mean } \pm \\
\text { SD }\end{array}$ & $\begin{array}{l}\text { Mean } \pm \\
\text { SD }\end{array}$ & & $\begin{array}{l}\text { Mean } \pm \\
\text { SD }\end{array}$ & $\begin{array}{l}\text { Mean } \pm \\
\text { SD }\end{array}$ & & $\begin{array}{l}\text { Mean } \pm \\
\text { SD }\end{array}$ & Mean \pm SD & $\begin{array}{l}\text { Mean } \pm \\
\text { SD }\end{array}$ & \\
\hline $\mathrm{DL}$ & 18.31 & 6.10 & 0.000 & $\begin{array}{l}2.70 \pm \\
1.86\end{array}$ & $\begin{array}{l}1.91 \pm \\
1.19\end{array}$ & 0.000 & $\begin{array}{l}6.33 \pm \\
2.07\end{array}$ & $\begin{array}{l}5.67 \pm \\
1.18\end{array}$ & 0.000 & $0.61 \pm 2.01$ & $0.79 \pm 1.38$ & $\begin{array}{l}-0.21 \pm \\
2.36\end{array}$ & NS \\
\hline DM & 63.38 & 27.70 & 0.000 & $\begin{array}{l}4.72 \pm \\
2.17\end{array}$ & $\begin{array}{l}3.18 \pm \\
1.57\end{array}$ & 0.000 & $\begin{array}{l}11.25 \pm \\
3.70\end{array}$ & $\begin{array}{l}4.57 \pm \\
1.34\end{array}$ & 0.000 & $6.62 \pm 3.88$ & $1.55 \pm 1.66$ & $5.03 \pm 4.00$ & 0.000 \\
\hline DB & 72.77 & 45.07 & 0.000 & $\begin{array}{l}5.43 \pm \\
2.29\end{array}$ & $\begin{array}{l}3.95 \pm \\
1.84\end{array}$ & 0.000 & $\begin{array}{l}13.92 \pm \\
2.74\end{array}$ & $\begin{array}{l}6.94 \pm \\
2.13\end{array}$ & 0.000 & $6.94 \pm 3.04$ & $1.50 \pm 1.59$ & $5.38 \pm 2.84$ & 0.000 \\
\hline $\begin{array}{l}\text { Mean } \\
\text { value }\end{array}$ & 51.49 & 26.29 & 0.000 & $\begin{array}{l}4.28 \pm \\
1.66\end{array}$ & $\begin{array}{l}3.01 \pm \\
1.28\end{array}$ & 0.000 & $\begin{array}{l}10.50 \pm \\
1.72\end{array}$ & $\begin{array}{l}5.73 \pm \\
1.27\end{array}$ & 0.000 & $4.72 \pm 1.86$ & $1.28 \pm 1.24$ & $3.38 \pm 1.84$ & 0.000 \\
\hline
\end{tabular}

DBD Distal intra-bony defect. PD at BL was the distance from the distal marginal ridge of the M2M to the bottom of the DBD. PD at Po.6 $\mathrm{m}$ was the distance from the distal marginal ridge of the M2M to the junctional epithelium. "NS" denotes "no significant difference" 

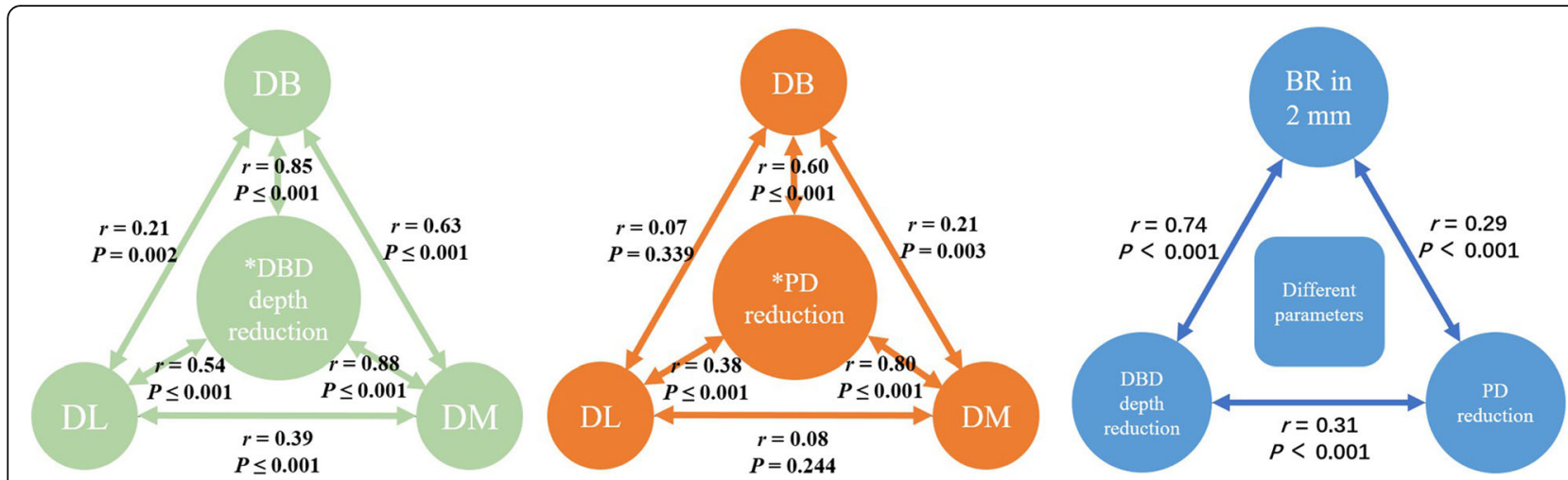

Fig. 2 Correlation between different sites and different parameters. $D B=$ disto-buccal; $D M=$ disto-middle; $D L=$ disto-lingual; $D B D=$ distal intrabony defect; $B R$ in $2 \mathrm{~mm}=$ volume of bone regenerated in the distal $2 \mathrm{~mm}$ of $\mathrm{M} 2 \mathrm{M}$

$\mathrm{mm})$ [10]. Eliminating overlap in 2D radiography, all distal sites (DL, DM, DB) of the M2M were assessed and a significant difference in the PD and DBD depth was found $(P \leq 0.001)$ (Table 1$)$. Po.6 $\mathrm{m}$ was chosen because the major part of periodontal healing occurs within 3 months after surgery [9]. The mean reduction in the DBD depth was $1.28 \pm 1.24 \mathrm{~mm}$, which is slightly higher than that documented in other studies $(0.62-1.25 \mathrm{~mm})$ $[4,6,13]$. Hence, the root complex did not disturb periodontal healing of the M2M. The change in the DBD depth $(r \geq 0.54)$ and PD $(r \geq 0.38)$ in all sites was corelated significantly with the mean value (Fig. 2). It was acceptable to use the mean value in subsequent statistical analyses.

The factors influencing periodontal healing of the M2M reported previously were analyzed in the present study. No significant difference was found between the DBD depth in patients younger than 25 years (4.08 \pm $1.77 \mathrm{~mm})$ and those older than 25 years $(4.45 \pm 1.56 \mathrm{~mm})$ $(P=0.105)$. However, 6 months later, patients younger than 25 years $(1.55 \pm 1.35 \mathrm{~mm})$ obtained a greater reduction in the DBD than their older counterparts $(1.07 \pm$
$1.10 \mathrm{~mm})(P=0.045)$. Correlation and regression analyses also showed a negative relationship between age and DBD reduction, and these observations were consistent with data from various studies [7, 29]. The original DBD depth has been reported to be a risk factor for periodontal healing of the M2M [7]. In the present study, a close correlation was shown between baseline and Po. $6 \mathrm{~m}(r=0.67, P \leq 0.001)$ for DBD depth. Besides, the higher DBD in our study $(5.43 \pm 2.29 \mathrm{~mm}$ at baseline, 72.8 to $45.1 \%$ ) explains why the decrease in the number of DB sites of DBD depth $\geq 4 \mathrm{~mm}$ was less than that reported in the study by Faria $(4.54 \pm 1.87 \mathrm{~mm}$ at baseline, 76.9 to $15.3 \%$ ) [10]. However, the DBD depth at baseline showed a positive correlation with DBD reduction, with the highest correlation coefficients being reported among all the factors evaluated in our study $(r=0.59$, $P \leq 0.001)$. These data suggested that compensatory bone formation would occur in patients with a large DBD depth at baseline, but their prognosis would not be better than that of patients with small DBD depth at baseline. These cases of coronectomy are important because the deeper the impaction of M3Ms preoperatively, the

Table 2 Correlation analyses of previously reported and coronectomy-related factors

\begin{tabular}{|c|c|c|c|c|c|c|c|c|c|c|c|c|}
\hline & & \multirow[b]{2}{*}{ Age } & \multicolumn{3}{|c|}{ M3M condition } & \multicolumn{2}{|c|}{$\begin{array}{l}\text { M2M } \\
\text { condition }\end{array}$} & \multicolumn{5}{|c|}{ Coronectomy-related factors } \\
\hline & & & $\begin{array}{l}\text { P\&G's } \\
\text { depth of } \\
\text { impaction }\end{array}$ & $\begin{array}{l}\text { Angulation } \\
\text { of } M 3 \mathrm{M}\end{array}$ & RMS & $\begin{array}{l}\text { DBD } \\
\text { depth } \\
\text { at BL }\end{array}$ & ERR & $\begin{array}{l}\text { Enamel } \\
\text { remains }\end{array}$ & $\begin{array}{l}\text { Root } \\
\text { migration }\end{array}$ & $\begin{array}{l}\text { Root } \\
\text { rotation }\end{array}$ & $\begin{array}{l}\text { Total volume } \\
\text { of bone } \\
\text { regenerated in } \\
\text { tooth socket }\end{array}$ & $\begin{array}{l}\text { Thickness of } \\
\text { calcification } \\
\text { bridge above } \\
\text { root section }\end{array}$ \\
\hline \multirow{2}{*}{$\begin{array}{l}\text { DBD depth } \\
\text { reduction }\end{array}$} & $r$ & -0.23 & 0.20 & 0.37 & -0.36 & 0.59 & -0.08 & -0.03 & 0.01 & 0.19 & -0.01 & 0.27 \\
\hline & P-value & 0.001 & 0.003 & 0.000 & 0.000 & 0.000 & NS & NS & NS & 0.005 & NS & 0.000 \\
\hline \multirow[t]{2}{*}{ PD reduction } & $r$ & -0.09 & 0.07 & 0.28 & -0.26 & 0.17 & -0.01 & -0.06 & 0.02 & 0.06 & -0.03 & 0.30 \\
\hline & P-value & 0.187 & 0.309 & 0.000 & 0.000 & 0.014 & NS & NS & NS & NS & NS & 0.000 \\
\hline \multirow{2}{*}{$\begin{array}{l}\text { Volume of } \\
\text { bone } \\
\text { regenerated } \\
\text { in distal } 2 \mathrm{~mm}\end{array}$} & $r$ & -0.21 & 0.28 & 0.43 & -0.44 & 0.42 & -0.04 & -0.02 & 0.09 & 0.24 & 0.20 & 0.25 \\
\hline & P-value & 0.002 & 0.000 & 0.000 & 0.000 & 0.000 & NS & NS & NS & 0.000 & 0.004 & 0.000 \\
\hline
\end{tabular}


Table 3 Factors influencing bone variation and re-contact of the root complex and M2M

\begin{tabular}{|c|c|c|c|c|}
\hline Multiple linear regression & Variables & B & Coef & $\mathbf{P}$ \\
\hline \multirow[t]{6}{*}{ DBD depth redution } & & & Adjusted $\mathrm{F}$ & \\
\hline & Age & -0.07 & -0.28 & 0.000 \\
\hline & RMS & -0.07 & -0.13 & 0.010 \\
\hline & DBD depth at $B L$ & 0.49 & 0.66 & 0.000 \\
\hline & Rotation of root complex & 0.02 & 0.12 & 0.020 \\
\hline & Eruption status of root complex & 0.50 & 0.19 & 0.000 \\
\hline \multicolumn{3}{|c|}{ Volume of bone regenerated in distal $2 \mathrm{~mm}$} & \multicolumn{2}{|c|}{ Adjusted $\mathrm{R}^{2}=0.417$} \\
\hline & Age & -1.21 & -0.23 & 0.000 \\
\hline & RMS & -1.76 & -0.17 & 0.009 \\
\hline & DBD depth at $B L$ & 5.69 & 0.36 & 0.000 \\
\hline & Rotation of root complex & 0.52 & 0.14 & 0.009 \\
\hline & Total volume of bone regenerated in tooth socket & 0.02 & 0.14 & 0.014 \\
\hline & Eruption status of root complex & 9.64 & 0.18 & 0.001 \\
\hline Binary logistic regression & Variables & OR & $95 \% C L$ & $\mathbf{P}$ \\
\hline \multicolumn{5}{|c|}{ Recontact of root complex and distal root surface of M2M } \\
\hline & RMS & 0.67 & $0.46-0.97$ & 0.035 \\
\hline & Enamel remains & 6.93 & $1.13-42.58$ & 0.037 \\
\hline
\end{tabular}

DBD Distal intra-bony defect, RMS Retromolar space. "NS" denotes "no significant difference"

larger was the DBD depth at baseline. Similarly, deep impaction and large angulation of the M3M could contribute to a large DBD depth at baseline, as shown previously $[3,10,30]$, and are related positively with DBD reduction $(r \geq 0.20, P \leq 0.003)$.

Some factors related to coronectomy and periodontal healing have not been studied before. The RMS reflects whether the width for M3M eruption is sufficient [27].
The RMS was corelated negatively with the depth of M3M impaction $(r=-0.28, P \leq 0.001)$. Significant correlation was observed between the RMS and reduction in DBD depth $(r=-0.36, P \leq 0.001)$. Thus, it is reasonable to assume that, after coronectomy of the M3M, patients with a small RMS could obtain a narrow and deep pocket distal to the M2M [16]. Sculean reported that that a narrow and deep pocket would gain more bone

Table 4 Different multiple linear regression models for PD reduction

\begin{tabular}{|c|c|c|c|c|}
\hline Independent factors included & Variables & B & Coef & $\mathbf{P}$ \\
\hline \multirow[t]{4}{*}{ Baseline factors } & Adjusted $\mathrm{R}^{2}=0.576$ & & & \\
\hline & Age & -0.05 & -0.13 & 0.006 \\
\hline & DBD depth at BL & -0.07 & -0.07 & NS \\
\hline & $\mathrm{PD}$ at $\mathrm{BL}$ & 0.85 & 0.78 & 0.000 \\
\hline \multirow[t]{5}{*}{ Baseline factors + hard tissue variation } & Adjusted $R^{2}=0.618$ & & & \\
\hline & Age & -0.01 & -0.03 & NS \\
\hline & DBD depth at BL & -0.33 & -0.30 & 0.000 \\
\hline & $\mathrm{PD}$ at $\mathrm{BL}$ & 0.86 & 0.79 & 0.000 \\
\hline & ${ }^{a} D B D$ depth reduction & 0.49 & 0.33 & 0.000 \\
\hline \multirow[t]{5}{*}{ Baseline factors + soft tissue variation } & Adjusted $\mathrm{R}^{2}=0.798$ & & & \\
\hline & Age & -0.07 & -0.19 & 0.000 \\
\hline & DBD depth at BL & 0.37 & 0.34 & 0.000 \\
\hline & $\mathrm{PD}$ at $\mathrm{BL}$ & 0.20 & 0.19 & 0.000 \\
\hline & \# Difference between PD reduction and DBD depth reduction & 0.73 & 0.73 & 0.000 \\
\hline
\end{tabular}

DBD Distal intra-bony defect, RMS Retromolar space. "NS" denotes "no significant difference"

Note: ${ }^{\text {aT }}$ The DBD depth was regarded to be a factor related hard-tissue variation. \#The difference between PD reduction and reduction in DBD depth was regarded to be a factor related to soft-tissue variation 
than a wide and shallow defect. Hence, a patient with a small RMS could gain more bone than a patient with a large RMS. Rotation of the root complex can be observed in $65 \%$ of patients after coronectomy [28]. The positive relationship between root rotation and reduction in DBD depth has been considered to be orthodontic traction [31]. A bone-embedded root complex regenerated more bone distal to the M2M than that observed for soft tissue-covered roots $(r=0.27, P \leq 0.001)$, data that are in accordance with results from a study by Yeung [23]. A correlation was not found between reduction in DBD depth and root migration, as reported previously [14, 31]. Analyses of the coronectomy-related factors mentioned above suggested that the remaining root complex did not disturb periodontal healing of the M2M. Re-contact of the root complex and distal surface of the M2M was a potential risk factor for the periodontal condition of the M2M; it caused two in five patients to undergo secondary surgery after coronectomy in a study by Monaco [32]. Meanwhile, a M3M with a complete root apex can erupt upon application of mechanical force to a M2M [33] and increase the risk of external root resorption [34]. Surgeons should note that the remaining enamel increased the risk of re-contact by 5.9-fold (OR $=6.93, P=0.037)$ and, for each $1-\mathrm{mm}$ decrease in the RMS, the risk of re-contact increased by $33 \%(0.67,0.035)$.

Healing processes among DB, DM and DL sites might have been different because of three different causes of bony defect. First, the periodontal condition at the DL site was much better than that at DM and DB sites. Periodontal healing at the DL site showed much less relevance than that at DM and DB sites (Fig. 2). DBD depth at the DL site $(1.91 \pm 1.19 \mathrm{~mm}$ at Po.6 m) was in accordance with the periodontalhealing standard that alveolar-bone height must be restored to within $2 \mathrm{~mm}$ of the CEJ [35]. Periodontal healing here could be characterized as normal healing of alveolar sockets. Second, defects at DM and DB sites were much deeper than those at the DL site (Table 1), and might have been caused by M3M growth. Chen studied $421 \mathrm{CBCT}$ images of M3Ms and found that $96.2 \%$ of M3Ms were at median or buccal sides distal to M2Ms [36]. Conversely, we found that PD reduction could be due more to softtissue variation than hard-tissue variation (Table 4). Most participants in the present study were asymptomatic, and a thickness of soft tissue $>5 \mathrm{~mm}$ at DM and DB sites (difference in reduction of DBD depth and PD reduction is shown in Table 1) would be considered to be the long junctional epithelium [16]. Also, the lack of keratinized gingival coverage might account for the vulnerability of the M3M region to periodontal diseases [37]. It would be better to prevent reduced growth of the epithelium and improve periodontal healing of the M2M with guided tissue regeneration [35]. Third, a defect at the $\mathrm{DB}$ site is also created (at least in part) by iatrogenic removal of buccal bone during M3M surgery [12]. A significant correlation between reduction in DBD depth and PD reduction was found between DM and DB sites (Fig. 2). However, the percentage of severe bone loss (DBD depth $\geq 4 \mathrm{~mm}$ ) was greater at the DB site $(72.8 \%$ at baseline, $45.1 \%$ at Po.6 $\mathrm{m})$ than that at the DM site $(63.4 \%$ at baseline, $27.7 \%$ at Po.6 $\mathrm{m})$ (Table 1).

Healing of a periodontal defect is based on recovery of surrounding alveolar bone [35]. Previous periodontal probing and 2D radiographs are not sufficient to evaluate morphology of bone pockets, which is critical for prediction of periodontal healing [16]. Furthermore, bone height does not to indicate the stability of periodontal healing. A more accurate and predictable index in three dimensions is necessary.

We proposed, for the first time, the volume of bone regenerated in the distal $2 \mathrm{~mm}$ of the M2M to be such an index. This parameter reflects the minimum thickness of bone required to prevent resorption of surrounding bone, and denotes the stability of bone distal to the M2M. Our postulation is based on two main observations. First, Porto reported, in an anatomic study, that the minimum thickness of stable alveolar bone in posterior teeth is $1.98 \pm 1.33 \mathrm{~mm}$ [38]. Second, it is widely accepted that $2 \mathrm{~mm}$ of alveolar width around the implant is the minimum volume to prevent further bone resorption [39]. When using digital software to measure bone volume, the error between the measured value and real value is relatively small. According to a study by Liu and colleagues [18], the deviation was $<7 \%$. Therefore, the accuracy of our new 3D index (the volume of bone regenerated in the distal $2 \mathrm{~mm}$ of the M2M) was sufficient for clinical application. The morphology of bone pockets is presented in Fig. 1g. A significantly high correlation was found between the volume of bone regenerated in the distal $2 \mathrm{~mm}$ and reduction in the DBD depth $(r=0.74, P<0.001)$. In addition, all statistical analyses involving these two factors revealed similar results, which provides further evidence of the effectiveness of this new index. Conversely, the volume of bone regenerated in the distal $2 \mathrm{~mm}$ showed a weak correlation with the total volume of bone regenerated in the alveolar socket $(r=0.20, P=0.004)$ whereas reduction in DBD depth did not $(r=-0.01$, $P=0.871$ ). Our new index might bridge the healing of the alveolar socket of the M3M and repair of distal periodontal tissue of the M2M. 
Our study had two main limitations. First, a control group (total extraction of the M3M) was not included. The reason was because coronectomy is widely accepted as an effective alternative to prevent IAN injury [2]. Also, our ethics committee suggested that random grouping might not suitable in our study. Second, age is a critical factor for DBD healing [29], but the patients recruited for our study were relatively young.

\section{Conclusions}

The DBD depth at baseline was the most influential factor for healing of a DBD of the M2M after M3M coronectomy. The remaining enamel and a small RMS could contribute to re-contact of the root complex and the $\mathrm{M} 2 \mathrm{M}$. The volume of bone regenerated in the distal 2 $\mathrm{mm}$ of the M2M was an accurate 3D indicator reflecting the stability of distal periodontal healing of the M2M.

\section{Abbreviations}

3D: Three-dimensional; 2D: Two-dimensional; BL: Baseline, the day after surgery; CBCT: Cone-beam computed tomography; CEJ: Cementoenamel junction; DB: Disto-buccal; DM: Disto-middle; DL: Disto-lingual; DBD: Distal intra-bony defect; DMR: Distal marginal ridge; IAN: The inferior alveolar nerve; M2M: Mandibular second molar; M3M: Mandibular third molar; PD: Probing depth; Po. 6 m: 6 months postoperatively; RMS: Retromolar space

\section{Acknowledgements}

We thank the assistant staff involved in this study. We gratefully acknowledge the digital engineer Jiyan Guo and Dr. Jun Kang in the Department of Periodontology for their excellent advice.

\section{Authors' contributions}

ZY Yan contributed to measurement of the digital model, data acquisition and manuscript writing. Y Tan assisted with the analyses and interpretation of data. XY Xie contributed to data collection and building of the digital model. W He helped with study design, digital-model building and manuscript revision. CB Guo contributed to study design, data interpretation, revision of the manuscript, and gave final approval for this version of the manuscript to be published. NH Cui designed, supervised the study and conducted all surgical procedures. He gave the final approval for this version of the manuscript to be published and agreed to be accountable for all aspects of this work. All authors reviewed the final version of the manuscript and approved it for publication.

\section{Funding}

This research was supported by the New Clinical Technique Project of the Peking University School and Hospital of Stomatology (PKUSSNCT-18A12).

\section{Availability of data and materials}

The datasets used and analyzed during the current study are available from the corresponding authors upon reasonable request.

\section{Ethics approval and consent to participate}

Ethical approval of the study protocol was granted by the Biomedical Ethics Committee of Peking University Hospital of Stomatology (PKUSSIRB201736080) in Beijing, China. All patients provided written informed consent to participate in this study.

\section{Consent for publication}

Not applicable.

\section{Competing interests}

The authors declare that they have no competing interests.

\section{Author details}

'Department of Oral and Maxillofacial Surgery, Peking University School and Hospital of Stomatology, 22 South Street Zhong Guan Cun, Haidian District, Beijing 100081, China. ${ }^{2}$ Department of Medical Statistics, Peking University Clinical Research Institute, Beijing, China. ${ }^{3}$ Department of Oral and Maxillofacial Radiology, Peking University School and Hospital of Stomatology, Beijing, China.

Received: 2 June 2020 Accepted: 9 September 2020

Published online: 24 September 2020

\section{References}

1. Pogrel MA, Lee JS, Muff DF. Coronectomy: a technique to protect the inferior alveolar nerve. J Oral Maxillofac Surg. 2004;62(12):1447-52.

2. Yan ZY, Yan XY, Guo CB, Xie QF, Yang GJ, Cui NH. Somatosensory changes in Chinese patients after coronectomy vs. total extraction of mandibularthird molar: a prospective study. Clin Oral Investig. 2020;24(9): 3017-28

3. Montero J, Mazzaglia G. Effect of removing an impacted mandibular third molar on the periodontal status of the mandibular second molar. J Oral Maxillofac Surg. 2011;69(11):2691-7

4. Krausz AA, Machtei EE, Peled M. Effects of lower third molar extraction on attachment level and alveolar bone height of the adjacent second molar. Int J Oral Maxillofac Surg. 2005;34(7):756-60.

5. Quee TA, Gosselin D, Millar EP, Stamm JW. Surgical removal of the fully impacted mandibular third molar. The influence of flap design and alveolar bone height on the periodontal status of the second molar. J Periodontol. 1985;56(10):625-30.

6. Andrade Munhoz E, Bodanezi A, Ferreira Junior O, Mauro Granjeiro J. Bone crestal height and bone density after third-molar extraction and grafting: a long-term follow-up study. Clin Oral Investig. 2011;15(1):123-6.

7. Passarelli PC, Lajolo C, Pasquantonio G, D'Amato G, Docimo R, Verdugo F, D'Addona A. Influence of mandibular third molar surgical extraction on the periodontal status of adjacent second molars. J Periodontol. 2019;90(8):847-55

8. Peng KY, Tseng YC, Shen EC, Chiu SC, Fu E, Huang YW. Mandibular second molar periodontal status after third molar extraction. J Periodontol. 2001; 72(12):1647-51.

9. Faria Al, Gallas-Torreira M, López-Ratón M. Mandibular second molar periodontal healing after impacted third molar extraction in young adults. Oral Maxillofac Surg. 2012;70(12):2732-41.

10. Inocêncio Faria A, Gallas-Torreira M, López-Ratón M, Crespo-Vázquez E, Rodríguez-Núñez I, López-Castro G. Radiological infrabony defects after impacted mandibular third molar extractions in young adults. J Oral Maxillofac Surg. 2013;71(12):2020-8.

11. Kan KW, Liu JK, Lo EC, Corbet EF, Leung WK. Residual periodontal defects distal to the mandibular second molar 6-36 months after impacted third molar extraction. J Clin Periodontol. 2002;29(11):1004-11.

12. Petsos $H$, Korte J, Eickholz $P$, Hoffmann $T$, Borchard R. Surgical removal of third molars and periodontal tissues of adjacent second molars. J Clin Periodontol. 2016:43(5):453-60.

13. Hassan KS, Marei HF, Alagl AS. Does grafting of third molar extraction sockets enhance periodontal measures in 30- to 35-year-old patients. J Oral Maxillofac Surg. 2012;70(4):757-64.

14. Vignudelli E, Monaco G, Gatto MR, Franco S, Marchetti C, Corinaldesi G. Periodontal healing distally to second mandibular molar after third molar Coronectomy. J Oral Maxillofac Surg. 2017:75(1):21-7.

15. Leung YY. Guided bone regeneration to reduce root migration after coronectomy of lower third molar: a randomized clinical trial. Clin Oral Investig. 2018;23(4):1595-604

16. Sculean A, Nikolidakis D, Nikou G, Ivanovic A, Chapple IL, Stavropoulos A. Biomaterials for promoting periodontal regeneration in human intrabony defects: a systematic review. Periodontol 2000. 2015;68(1):182-216.

17. Feifel $H$, Riediger $D$, Gustorf-Aeckerle R. High resolution computed tomography of the inferior alveolar and lingual nerves. Neuroradiology. 1994;36(3):236-8.

18. Liu Y, Olszewski $R$, Alexandroni ES, Enciso R, Xu T, Mah JK. The validity of in vivo tooth volume determinations from cone-beam computed tomography. Angle Orthod. 2010:80(1):160-6.

19. Sang YH, Hu HC, Lu SH, Wu YW, Li WR, Tang ZH. Accuracy assessment of three-dimensional surface reconstructions of in vivo teeth from cone-beam computed tomography. Chin Med J. 2016;129(12):1464-70. 
20. Flügge T, Derksen W, Te Poel J, Hassan B, Nelson K, Wismeijer D. Registration of cone beam computed tomography data and intraoral surface scans - a prerequisite for guided implant surgery with CAD/CAM drilling guides. Clin Oral Implants Res. 2017;28(9):1113-8.

21. Eggers G, Mühling J, Hofele C. Clinical use of navigation based on conebeam computer tomography in maxillofacial surgery. $\mathrm{Br} J$ Oral Maxillofac Surg. 2009;47(6):450-4.

22. Bergström J, Eliasson S. Cigarette smoking and alveolar bone height in subjects with a high standard of oral hygiene. J Clin Periodontol. 1987;14(8):466-9.

23. Yeung A, Wong N, Bornstein MM, Leung YY. Three-dimensional radiographic evaluation of root migration patterns 4-8.5 years after lower third molarcoronectomy: a cone beam computed tomography study. Int J Oral Maxillofac Surg. 2018;47(9):1145-52.

24. Goto S, Kurita K, Kuroiwa Y, Hatano Y, Kohara K, Izumi M, Ariji E. Clinical and dental computed tomographic evaluation 1 year after coronectomy. J Oral Maxillofac Surg. 2012;70(5):1023-9.

25. González-Martín O, Veltri M, Moráguez O, Belser UC. Quantitative threedimensional methodology to assess volumetric and profilometric outcome of subepithelial connective tissue grafting at pontic sites: a prospective pilot study. Int J Periodontics Restorative Dent. 2014;34(5):673-9.

26. Tian J, Wei D, Zhao Y, Di P, Jiang X, Lin Y. Labial soft tissue contour dynamics following immediate implants and immediate provisionalization ofsingle maxillary incisors: A 1-year prospective study. Clin Implant Dent Relat Res. 2019;21(3):492-502.

27. Mollaoglu N, Cetiner S, Güngör K. Patterns of third molar impaction in a group of volunteers in Turkey. Clin Oral Investig. 2002;6(2):109-13.

28. Pedersen MH, Bak J, Matzen LH, Hartlev J, Bindslev J, Schou S, Nørholt SE. Coronectomy of mandibular third molars: a clinical and radiological study of 231 cases with a mean follow-up period of 5.7years. Int J Oral Maxillofac Surg. 2018;47(12):1596-603.

29. Kugelberg CF, Ahlström U, Ericson S, Hugoson A, Thilander $\mathrm{H}$. The influence of anatomical, pathophysiological and other factors on periodontal healing after impacted lower third molar surgery. A multiple regression analysis. J Clin Periodontol. 1991;18(1):37-43.

30. Kugelberg CF, Ahlström U, Ericson S, Hugoson A, Kvint S. Periodontal healing after impacted lower third molar surgery in adolescents and adults. A prospective study. Int J Oral Maxillofac Surg. 1991;20(1):18-24.

31. Monaco G, de Santis G, Gatto MR, Corinaldesi G, Marchetti C. Coronectomy: a surgical option for impacted third molars in close proximity to the inferior alveolar nerve. J Am Dent Assoc. 2012;143(4):363-9.

32. Monaco G, D'Ambrosio M, De Santis G, Vignudelli E, Gatto M, Corinaldesi G. Coronectomy: a surgical option for impacted third molars in close proximity to the inferior alveolar nerve-a 5-year follow-up study. J Oral Maxillofac Surg. 2019;77(6):1116-24.

33. Sandhu S, Kaur T. Radiographic study of the positional changes and eruption of impacted third molars in young adults of an Asian Indian population. J Oral Maxillofac Surg. 2008;66(8):1617-24.

34. Wang D, He X, Wang Y, Li Z, Zhu Y, Sun C, Ye J, Jiang H, Cheng J. External root resorption of the second molar associated with mesially and horizontally impacted mandibular third molar: evidence from cone beam computed tomography. Clin Oral Investig. 2017;21 (4):1335-42.

35. Bartold PM, McCulloch CA, Narayanan AS, Pitaru S. Tissue engineering: a new paradigm for periodontal regeneration based on molecular and cell biology. Periodontol 2000. 2000;24:253-69.

36. Chen Y, Zheng J, Li D, Huang Z, Huang Z, Wang X, Zhang X, Hu X. Threedimensional position of mandibular third molars and its association with distal caries in mandibular second molars: a cone beam computed tomographic study. Clin Oral Investig. 2020;24(9):3265-73.

37. Blakey GH, Golden BA, White RP Jr, Offenbacher S, Phillips C, Haug RH. Changes over time in the periodontal status of young adults with no third molar periodontal pathology at enrollment. J Oral Maxillofac Surg. 2009;67(11):2425-30.

38. Porto O, Silva B, Silva JA, Estrela C, Alencar A, Bueno M, Estrela C. CBCT assessment of bone thickness in maxillary and mandibular teeth: an anatomic study. J Appl Oral Sci. 2020;28:e20190148.

39. Qahash M, Susin C, Polimeni G, Hall J, Wikesjö UM. Bone healing dynamics at buccal peri-implant sites. Clin Oral Implants Res. 2008;19(2):166-72.

\section{Publisher's Note}

Springer Nature remains neutral with regard to jurisdictional claims in published maps and institutional affiliations.

\section{Ready to submit your research? Choose BMC and benefit from}

- fast, convenient online submission

- thorough peer review by experienced researchers in your field

- rapid publication on acceptance

- support for research data, including large and complex data types

- gold Open Access which fosters wider collaboration and increased citations

- maximum visibility for your research: over $100 \mathrm{M}$ website views per year

At BMC, research is always in progress.

Learn more biomedcentral.com/submissions 